\title{
The Demand of Urban Consumers for Safe Pork in the Vietnamese Mekong Delta
}

\author{
Huynh Viet Khai*, Tran Thi Thu Duyen \& Huynh Thi Dan Xuan \\ School of Economics, Can Tho University, Vietnam \\ hvkhai@ctu.edu.vn
}

\begin{abstract}
This study applied the contingent valuation method to analyze the consumers' demand for the proposed safe pork. The data was collected by face-to-face interviewing 884 urban households in the Vietnamese Mekong Delta. The results revealed that the majority of consumers (about 64\%) paid attention to the proposed safe pork. Their willingness to pay was about VND 176,000 (\$7.65) per kg, nearly double compared to the market price of conventional pork. The results showed that the respondents who had higher household income, larger proportion of elderly and children in the family, paid higher price of a conventional pork, and get more knowledge score on the safe pork are more likely, while the respondents who have more number of family members are less likely to pay for the proposed safe pork.
\end{abstract}

Keywords: Contingent valuation method, Safe pork, Consumer preferences, Willingness to pay

\section{Introduction}

In recent years, the living standard of Vietnamese has been gradually improved. Average income per capita in 2014 is $\$ 2,028$ per year, rising $6.31 \%$ compared to $2013^{1}$. Since then the demand for food has also increased. The International Business Monitor forecasts that Vietnam's food consumption in 2011-2016 continue to grow at 5.1\% per year, estimated at VND 538.4 million ( $\$ 29.5$ billion). Besides vegetables, meat is major food in the meal of Vietnamese families, so the consumption of pork products accounts for $75 \%$ of the annual demand for meat. Therefore, the domestic pig breeding industry has constantly improved and developed in order to meet the needs of domestic consumers. In the first six months of 2015, the total amount of pork supplied to the market reach 2.51 million tons, approximate $3.66 \%$ increase compared to the same period in $2014^{2}$. Although the quantity of pork supplied increases gradually, the quality of pork seriously declines because slaughtering process does not meet veterinary hygiene standards, the process of transportation and storage of the meat does not guarantee food safety ${ }^{3}$. Thus pork is infected with bacteria and nutrition in pork is degraded. In addition, injecting water into pork to increase the weight also occurs in recent years. Hence consumers not only buy underweight pork but also face the risk of unsafe food ${ }^{4}$.

Moreover, many slaughterhouses also inject a sedative (Prozil fort, Combitress) on pigs prior to slaughter for the purpose of easier slaughter and keeping pork look softer and nicer ${ }^{5}$. Besides, in the process of raising many ranchers use antibiotics, growth drugs to achieve maximum profit in the shortest time. These meats contain harmful substances, which banned from use in livestock production, can cause a number of diseases such as hypertension, respiratory failure, intestinal disease, even cancer and adversely affecting the development of children ${ }^{6}$. According to the World Health Organization, every year worldwide occurs about 40 million cases of poisoning. Half of all deaths in the world are related to food, foodstuff. Especially, the Asia Pacific region accounted for $50 \%$. Because of the extremely serious consequences of using contaminated pork, safe pork should be necessary for all consumers. However, safe pork concept is still relatively new to the consumers in Vietnam. The approach of the contingent valuation method (CVM) to estimate consumers' demand for safe products is widely used in the world. A study by Miller \& Unnevehr (2001) on consumers' demand and their willingness to pay (WTP) for a safe pork showed that most consumers in the US were interested in the issue of safe pork and their trust in safe pork products certified by the US Department of Agriculture more than the products certified by other organizations.

\footnotetext{
${ }^{1}$ Nghia, 2015

${ }^{2}$ Hieu, 2015

${ }^{3}$ Dinh, 2015

${ }^{4}$ Ngan \& Chien, 2015; Bach, 2015

${ }^{5}$ Ngan \& Chien, 2015; Thai \& Minh, 2015

${ }^{6}$ Anh, 2015; Uyen, 2015; Han, 2015
} 
Therefore, up to $81.4 \%$ of consumers accepted to pay more for pork products with this safe certification. Another study in Georgia done by Wong (2009) showed that 53\% of consumers agreed to pay higher for environmentally friendly beef. He found that respondents with higher education, previous history of purchasing branded goods and how more concerned they were about the environment were more likely to buy beef commodities produced with environmentally sound techniques. In Vietnam, most of the previous studies used the CVM to estimate WTP for biodiversity conservation or the economic value of recreation. The study of Dan \& Duyen (2010) estimated households' willingness to pay in Can Tho city for Sarus Crane conservation. They agreed to contribute about VND 12,222 per household a month for the proposed conservation program. In addition, the study revealed those bid levels, respondent's education, household income, knowledge of respondent about the current status of Sarus Crane and respondent belief in the success of conservation program are factors affecting on the probability of willingness to pay. Another study done by Khoi \& Ngan (2014) showed that Mekong Delta residents were willing to contribute about VND 9.5 million annually for the biodiversity conservation program in Bac Lieu bird garden.

There are few previous studies related to safe products in Vietnam. Simmons and Scott (2008) determined the agro-food system sustainability by summarizing the trends and prospects for organic agriculture in Vietnam. The results showed that organic production in Vietnam was mainly demanded by exporters, not due to the environmental concerns of domestic consumers. Vietnamese consumers paid high attention to food safety and food quality, but the development of organic products in the country was not so much. Dam et al. (2012) showed the unimportant role of organic farming in the Vietnamese agriculture sector and a lack of government policies to encourage the development of organic farming. Hai et al. (2013) recognized that fifteen percent of the consumers used to consume organic vegetables in Hanoi and they were willing to pay a premium of $70 \%$ higher for organic vegetables. A recent study of Khai (2015) showed that urban residents in the Vietnamese Mekong Delta were willing to pay VND 12,733 for $1 \mathrm{~kg}$ of safe vegetables, which was $59 \%$ higher than conventional vegetables in the market. The study also pointed out that those who cared about health issues and food safety, those who had high income and high education would be willing to pay more for safe vegetables.

To provide a larger picture or more information on safe products, this study applied the approach of CVM to determine consumer demand for the proposed safe pork by analyzing the interview data of urban residents in the Vietnamese Mekong Delta. The results of the study might be useful information to suggest some policy implications for promoting and developing the future market of the safe pork in this region. The paper is designed as follows. The following section introduces the approach of CVM to estimate the consumer demand for the proposed safe pork and the descriptions of data collection. After that, the results and some discussion on urban consumer demand for safe pork are reported. Finally, the conclusions are withdrawn from the results of the study.

\section{Methodology}

The CVM is applied to estimate the demand for the proposed safe pork in this study. Robert (1963) firstly applied the CVM to identify the benefits of outdoor recreation in Maine backwoods and then Ridker (1971) used to solve the problems of air pollution. After that, many economists applied the CVM to determine the benefits of many goods and services such as recreation, hunting, water quality, decreased mortality risk from a nuclear power plant accident and toxic waste dumps (Wattage, 2002). Despite some arguments on the correction of CVM results, most economists accepted that the results of the CVM were valuable and reliable if this method was carefully designed or constructed (e.g., Yao \& Kaval, 2008; Venkatachalam, 2004; Carson et al., 2001). Hanemann \& Kanninen (1998) assumed that a respondent was requested to choose a change from $Q^{0}$ to $Q^{1}\left(Q^{1}\right.$ presents the value of non-existent goods, such as safe pork, and assume $Q^{1}$ is preferred to $\left.Q^{0}\right)$. A utility function is described as follows, $V=V(P, Q, I, Z, \varepsilon)$, where $P$ is the price vectors of all available market goods, $I$ is the respondent's income, $Z$ is the vectors of respondent's social - economic characteristics, and $\varepsilon$ is the error term of utility function.

Then, the respondent is requested if he or she is willing to pay $t$ amount to obtain $Q^{1}$, the respondent will say "yes" if:

$$
\operatorname{Pr}(Y e s)=\operatorname{Pr}\left\{V\left(P, Q^{1}, I-t, Z\right)+\varepsilon 1 \geq V\left(P, Q^{0}, I-0, Z\right)+\varepsilon 0\right\}
$$




$$
=\operatorname{Pr}\left\{V\left(P, Q^{1}, I-t, Z\right)-V\left(P, Q^{0}, I-0, Z\right)+\varepsilon_{1}-\varepsilon_{0} \geq 0\right\}
$$

where, $\varepsilon_{o}$ and $\varepsilon_{1}$ are undeterministic components of utility function, with the expected value is zero and independent and identically distributed (i.i.d). If we consider $\Delta V=V\left(P, Q^{1}, M-t, Z\right)-V\left(P, Q^{0}, M-0, Z\right)$ and $\gamma=\varepsilon_{1}-\varepsilon_{0}$, equation (1) becomes:

$$
\operatorname{Pr}(Y e s)=\operatorname{Pr}(\gamma \geq-\Delta V)=1-F_{\gamma}(-\Delta V)=F_{\gamma}(\Delta V)
$$

where $F_{\gamma}(\Delta V)$ is Cumulative distribution function (cdf) of maximum willingness to pay.

The mean and median of willingness to pay in the CVM are estimated based on the constant of regression, the coefficient of BID and the coefficients of other variables such as awareness, attitude and socioeconomic characteristics. To identify factors influencing the WTP in CVM, the approach of Probit and Logit model are popularly applied. This study applies a Logit model with the estimated formula as follows,

$$
\begin{aligned}
& \operatorname{Pr}(\text { Yes })=F_{\gamma}(\Delta V)=\frac{1}{1+\exp (-\Delta V)}=\frac{1}{1+\exp -\left(\alpha+\beta_{1} B I D+\beta_{2} X\right)} \\
& \operatorname{Pr}(\text { Yes })=\operatorname{Pr}\left(R_{k}=1\right)=\operatorname{Pr}\left(\gamma_{\mathrm{k}} \leq \Delta V_{k}\right)=F_{\gamma}\left(\Delta V_{k}\right) \\
& \operatorname{Pr}(\text { No })=\operatorname{Pr}\left(R_{k}=0\right)=1-\operatorname{Pr}\left(\gamma_{\mathrm{k}} \leq \Delta V_{k}\right)=1-F_{\gamma}\left(\Delta V_{k}\right)
\end{aligned}
$$

Hence, log - likelihood function is constructed as follows,

$$
\log L=\sum_{k=1}^{N}\left\{R_{k} \ln \left(F_{\gamma}\left(\Delta V_{k}\right)+\left(1-R_{k}\right) \ln \left(1-F_{\gamma}\left(\Delta V_{k}\right)\right)\right\}\right.
$$

With the assumption of linear correlation, the mean and median WTP are equal and identified by following equation:

$$
\text { Mean } W T P=\text { Median } W T P=-\frac{\left(\widehat{\alpha}+\widehat{\beta_{2}} \bar{X}\right)}{\widehat{\beta_{1}}}
$$

\section{Data Collection}

Face-to-face interviews with urban residents in the Vietnamese Mekong Delta was conducted in 2016 and divided into two phases. The first phase is a pilot survey to check the appropriateness of the questionnaire as well as train interviewers. In the second phase, a survey with 884 urban respondents was done in the seven provinces of the Vietnamese Mekong Delta (Can Tho, Vinh Long, Hau Giang, Kien Giang, Soc Trang, Ca Mau, Bac Lieu) with random sampling method. In the questionnaire, the benefits of the proposed safe pork were introduced before CVM question was asked. It was assumed that the proposed safe pork that meets the standards of food safety and certified by a prestigious Veterinary Department was produced and sold in the market and its quality is similar to a conventional one. Respondents were asked to accept to pay a higher price for the proposed safe pork compared with the price of conventional one supposed to be VND 90,000 (\$3.91) per $\mathrm{kg}^{7}$. Each respondent was asked if he/she would be willing to buy the proposed safe pork at a given bid value and the answer was 'yes' or 'no'. Five different bid values ${ }^{8}$ are proposed as VND 110,000, VND 130,000, VND 150,000 , VND 170,000 and VND 190,000 per kg, which are equal to the values in US dollars ${ }^{9}$ of $\$ 4.78, \$ 5.65$, $\$$ $6.52, \$ 7.39$ and $\$ 8.26$, respectively.

\section{Results and Discussion}

To assess respondents' knowledge about the production process as well as the current consumption of pork, a series of statements about unsafe food in the production and consumption of pork was presented. The awareness of respondents about this issue are presented in Table 1. The results in Table 1 reveal that most consumers now regularly updated information on the issues of food safety in general and the troubles in the production and consumption of pork in particular. Therefore, consumers lose confidence in the quality of pork in the market, even some of them decrease the amount of pork consume and switched to the consumption of alternative products. Hence, if safe pork products that ensure all the criteria as above assumptions appear in the market, then the products will get more support from consumers. After answering questions related to the knowledge of the safe pork, a scenario was shown to respondents that the safe pork would appear in the market and the product meets the criteria of food safety and would be good for consumer's health. Then, the CVM question was asked that whether the respondent was willing to buy the

\footnotetext{
${ }^{7}$ The price is identified by averaging the prices of all conventional pork products at the time of study.

${ }^{8}$ These are mean prices for all kinds of safe pork products

$91 \mathrm{USD}=23,000 \mathrm{VND}$
} 
proposed safe pork at a higher price than conventional pork in the current market or not. The number of respondents agrees to pay for the safe pork at given prices are shown in Table 2 .

Table 1: Respondents' Knowledge About Safe Pork Issues

\begin{tabular}{|c|c|c|c|}
\hline Statements & Unknow & Know a little & Know a lot \\
\hline $\begin{array}{l}\text { The current processes of pig slaughter in most } \\
\text { slaughterhouses do not meet the hygiene standards set } \\
\text { by the Veterinary Department, quarantine stages before } \\
\text { and after slaughtering are loose }{ }^{10}\end{array}$ & $\begin{array}{c}194 \\
(21.95 \%)\end{array}$ & $\begin{array}{c}366 \\
(41.4 \%)\end{array}$ & $\begin{array}{c}324 \\
(36.65 \%)\end{array}$ \\
\hline $\begin{array}{l}\text { Current pork quality is not guaranteed because farmers } \\
\text { use special food to gain weight during the breeding } \\
\text { process; sedative and water injection into the pigs before } \\
\text { slaughtering } 11\end{array}$ & $\begin{array}{c}81 \\
(9.16 \%)\end{array}$ & $\begin{array}{c}349 \\
(39.48 \%)\end{array}$ & $\begin{array}{c}454 \\
(51.36 \%)\end{array}$ \\
\hline $\begin{array}{l}\text { Pork origin is unclear because the poor quality of pork } \\
\text { smuggled across borders occurs regularly }\end{array}$ & $\begin{array}{c}275 \\
(31.11 \%)\end{array}$ & $\begin{array}{c}360 \\
(40.72 \%)\end{array}$ & $\begin{array}{c}249 \\
(28.17 \%)\end{array}$ \\
\hline $\begin{array}{l}\text { The poor quality of pork is also used for producing a } \\
\text { variety of other products such as sausages, rolls which } \\
\text { negatively affect the consumer health }{ }^{12}\end{array}$ & $\begin{array}{c}188 \\
(21.27 \%)\end{array}$ & $\begin{array}{c}386 \\
(43.67 \%)\end{array}$ & $\begin{array}{c}310 \\
(35.06 \%)\end{array}$ \\
\hline $\begin{array}{l}\text { In the preservation of meat during sale time, the meat is } \\
\text { often salted by saltpetre and borax to keep fresh and } \\
\text { beautiful color, which does not guarantee food safety } \\
\text { standard } 13\end{array}$ & $\begin{array}{c}112 \\
(12.67 \%)\end{array}$ & $\begin{array}{c}346 \\
(39.14 \%)\end{array}$ & $\begin{array}{c}426 \\
(48.19 \%)\end{array}$ \\
\hline
\end{tabular}

Source: Surveyed data, 2016

The results from Table 2 show that $64 \%$ of respondents agree to pay for the safe pork, while the remaining $36 \%$ of respondents did not agree to pay for this product. The rate of respondents not willing to pay is a relatively high and majority distributed to the price of VND 170,000 and VND 190,000. In particular, at the lowest price of VND 110,000 , there are $83 \%$ of respondents agreeing to pay. There are $77 \%$ and $67 \%$ of respondents agreeing to pay at the price of VND 130,000 and VND 150,000 respectively. The rate of respondents willing to pay continue to decrease to $54 \%$ and $41 \%$ when the price increase to VND 170,000 and VND 190,000 respectively. Generally, the numbers of respondents who agree to pay decrease when the prices increase. This result is entirely consistent with the economic theory.

Table 2: Consumers Willing to Pay or Unwilling to Pay for the Proposed Safe Pork

\begin{tabular}{lccccc}
\hline Bid levels & No. & \multicolumn{2}{c}{ Willing to pay } & \multicolumn{2}{c}{ Unwilling to pay } \\
& Observations & Frequency & Percent (\%) & Number & Percent (\%) \\
\hline 110,000 & 177 & 147 & 83 & 30 & 17 \\
130,000 & 177 & 137 & 77 & 40 & 23 \\
150,000 & 177 & 118 & 67 & 59 & 33 \\
170,000 & 176 & 95 & 54 & 81 & 46 \\
190,000 & 177 & 73 & 41 & 104 & 59 \\
Total & $\mathbf{8 8 4}$ & $\mathbf{5 7 0}$ & $\mathbf{6 4}$ & $\mathbf{3 1 4}$ & $\mathbf{3 6}$ \\
\hline
\end{tabular}

Source: surveyed data, 2016

Table 3 presents the reasons why respondents disagree to pay for safe pork. Most of all respondents $(82.17 \%)$ are not willing to pay for the safe pork because they could not afford to pay for the given price, which was too higher than the price of conventional pork in the market. More than $50 \%$ of respondents do

\footnotetext{
10 Dinh (2015)

${ }^{11}$ Ngan \& Chien (2015)

${ }^{12}$ Anh (2015)

${ }^{13}$ Nguyen (2014)
} 
not want to pay for the following reasons: they declared that the standard of safe meat was just an excuse to raise the price; they could not distinguish whether it was a safe meat or not; they did not need to pay more for the safe pork because they thought almost foods in the market were contaminated or poor quality food. Moreover, $30.57 \%$ of respondents did not accept to pay because they did not believe that the safe pork would be of better quality than other conventional pork. Most previous studies suggest that the WPT is influenced by some social and economic factors such as income, age, gender and occupation. This study proposed some variables affecting the willingness to pay for the safe pork and the descriptive statistics of these variables are introduced in Table 4.

Table 3: Reasons for Consumer's Unwillingness to Pay

\begin{tabular}{lcc}
\hline Reasons & Number & Percent (\%) \\
\hline Do not distinguish whether it is a safe product & 166 & 52.87 \\
Cannot afford to pay for this price & 258 & 82.17 \\
Meat safety standards is just an excuse to raise the price & 170 & 54.14 \\
No need to pay more for this product & 162 & 51.59 \\
Do not believe the safe pork products will have better quality than & 96 & 30.57 \\
other common pork products & 19 & 6.05 \\
\hline Others & & \\
\hline
\end{tabular}

Source: surveyed data, 2016

Descriptive statistics in Table 4 shows that the average household income of respondents is at VND 10 million per person a month. On average, each household consumes $1.8 \mathrm{~kg}$ pork per week. Nearly $73 \%$ of respondents have dependents and $22 \%$ of respondents are housewives. The average age of the household head is 45 and $49 \%$ of respondents have an education level of college or higher. Their knowledge score (3 points) is rather high, revealing that most households know clearly the information on unsafe pork issues. Currently the respondents purchased an average price of conventional pork in the market is around VND 78,500 per kg. About $6 \%$ of respondents decided not to pay for other reasons such as the production of safe food is an obligation of the producer, the government should subsidize this product this is a task of the authorities.

Table 4: Descriptive Statistics of Variables in the Logit Model

\begin{tabular}{|c|c|c|c|}
\hline Variables & Description & Mean & Standard deviation \\
\hline Y & $\begin{array}{l}\text { Agree to pay for the proposed safe pork } \\
(1=\text { yes, } 0=\text { no })\end{array}$ & 0.644 & 0.479 \\
\hline BID & $\begin{array}{l}\text { Price of the proposed safe pork } \\
\text { (thousand VND } / \mathrm{kg} \text { ) }\end{array}$ & 149.977 & 28.208 \\
\hline INCOME & Household income (million VND/month) & 10.081 & 6.365 \\
\hline PORK VOLUME & $\begin{array}{l}\text { The average volume of consumed pork } \\
\text { (kg/week) }\end{array}$ & 1.784 & 1.243 \\
\hline DEPENDENT_RATE & $\begin{array}{l}\text { The proportion of the elderly and } \\
\text { children in the family }\end{array}$ & 0.726 & 0.446 \\
\hline AGE & The age of the household head (years) & 44.414 & 12.684 \\
\hline HIGH EDUCATION & $\begin{array}{l}\text { Dummy variable, } 1=\text { if the head } \\
\text { completed college or higher, } 0=\text { others }\end{array}$ & 0.490 & 0.500 \\
\hline HOUSEWIFE & $\begin{array}{l}\text { Dummy variable, } 1=\text { if the head is a } \\
\text { housewife, } 0=\text { others }\end{array}$ & 0.219 & 0.414 \\
\hline PRICE_CO_PORK & $\begin{array}{l}\text { Price of conventional pork (thousand } \\
\text { VND } / \mathrm{kg} \text { ) }\end{array}$ & 78.551 & 11.088 \\
\hline KNOWLEDGE $\psi$ & $\begin{array}{l}\text { Total score of the knowledge question } \\
\text { about safe pork (points) }\end{array}$ & 3.016 & 1.317 \\
\hline FAMILY NUMBERS & Numbers of family member (persons) & 4.581 & 2.199 \\
\hline
\end{tabular}

Note: $\Psi$ Each respondent was asked 5 questions about the status of current production and consumption of pork presented in Table 1. The respondent would be scored 1 point if said "Yes, I know a lot" or "Yes, I know a little", and 0 if said "I do not know"

Source: surveyed data, 2016 
Table 5 shows Logit results of consumer's willingness to pay for the safe pork. Model 1 is a Logit regression with only one independent variable (BID), while the Logistic regression in Model 2 including the variables of respondent's characteristics and other important factors influencing the probability of WTP for the safe pork. The results show that the correct prediction of the first model is $67.99 \%$ and the second model is $70.81 \%$. These numbers suggest that all two models are adequate and acceptable. The study also shows the absence of multicollinearity among the independent variables in these models because the correlations among independent variables are less than 70 percent (Khai and Yabe, 2013; 2015). The results show that the average willingness of consumers in Model 1 is VND 177,000 per kg, and Model 2 is VND 176,000 per kg. Two Logit regressions indicate that the BID variables are negative and significant at the $1 \%$ level, which means that the higher the VND amount the respondents are asked to pay, the lower the probability that the respondents accept to pay for the safe pork.

Table 5: Logit Results of Consumer's Willingness to Pay for the Safe Pork

\begin{tabular}{|c|c|c|c|c|c|c|}
\hline \multirow{3}{*}{ Variables } & \multirow{2}{*}{\multicolumn{2}{|c|}{ Model 1}} & \multicolumn{4}{|c|}{ Model 2} \\
\hline & & & \multicolumn{2}{|c|}{ Probit function } & \multicolumn{2}{|c|}{ Marginal effect } \\
\hline & Coef. & S.E. & Coef. & S.E. & $\mathrm{DY} / \mathrm{dx}$ & S. E. \\
\hline BID & $-0.0251^{* * *}$ & 0.0028 & $-0.0269 * * *$ & 0.0029 & $-0.0052^{* * *}$ & 0.0005 \\
\hline INCOME & & & $0.0458^{* * *}$ & 0.0137 & $0.0090^{* * *}$ & 0.0026 \\
\hline PORK VOLUME & & & -0.0710 & 0.0638 & -0.0139 & 0.0124 \\
\hline DEPENDENT_RATE & & & $0.3101^{*}$ & 0.1829 & $0.0610^{*}$ & 0.0356 \\
\hline AGE & & & -0.0089 & 0.0062 & -0.0017 & 0.0012 \\
\hline HIGH EDUCATION & & & -0.1552 & 0.1626 & -0.0303 & 0.0317 \\
\hline HOUSEWIFE & & & 0.1435 & 0.1889 & 0.0280 & 0.0368 \\
\hline PRICE_CO_PORK & & & $0.0199^{* * *}$ & 0.0074 & $0.0039^{* * *}$ & 0.0014 \\
\hline KNOWLEDGE & & & $0.1996^{* * *}$ & 0.0594 & $0.0390^{* * *}$ & 0.0113 \\
\hline FAMILY NUMBERS & & & $-0.1540^{* * *}$ & 0.0413 & $-0.0301^{* * *}$ & 0.0078 \\
\hline Constant & $4.4250^{* * *}$ & 0.4356 & $3.1523^{* * *}$ & 0.7794 & & \\
\hline Log likelihood value & \multicolumn{2}{|c|}{-529.3551} & \multicolumn{2}{|c|}{-507.4911} & & \\
\hline Pseudo R-squared & \multicolumn{2}{|c|}{0.0796} & \multicolumn{2}{|c|}{0.1176} & & \\
\hline Correct prediction (\%) & \multicolumn{2}{|c|}{67.99} & \multicolumn{2}{|c|}{70.81} & & \\
\hline $\begin{array}{l}\text { Mean/Median WTP } \\
\text { (VND/kg) }\end{array}$ & \multicolumn{2}{|c|}{$\begin{array}{c}176,620 \\
(170,040-185,170)\end{array}$} & \multicolumn{4}{|c|}{$\begin{array}{c}176,180 \\
(169,810-184,180)\end{array}$} \\
\hline
\end{tabular}

Notes: Values in parentheses are standard deviations 95\% CI: 95\% confident interval is estimated by Krinsky and Robb method (1986) ***, ** and * significant at $1 \%, 5 \%$ and $10 \%$.

Source: Surveyed data, 2016

The results show the values of Pseudo R-squared and log-likelihood in Model 2 higher than those in Model 1, revealing the parametric fit level of Model 2 higher than that of Model 1. The value of Swait-Louviere loglikelihood ratio ${ }^{14}$ is $L R=-2\left(L_{1}-L_{2}\right)=-2(-529,3551-(-507,4911))=43,73$ which is more than the critical value of Chi-square distribution of 21.67 at the $1 \%$ significance level on 9 degrees of freedom ${ }^{15}$ (Khai, 2015), showing that the data estimation in Model 2 is better fit than Model 2. Thus, the results of Model 2 will be used as final interpretations. Consistently with the results of previous studies (e.g. Khai, 2015; Khai \& Yabe, 2014; 2015; Yin et al., 2010; Tsakiridou et al, 2008; Loureiro \& Hine, 2002;), the sign of INCOME parameter is positive and statistically significant at $1 \%$ level, suggesting the respondents who have higher household income are more likely to purchase the proposed safe pork. Similar to other studies (Khai \& Yabe, 2015; Dan \& Duyen, 2010), the study reveals that respondents who have more knowledge score on the safe pork prefer the proposed safe pork and who consume higher price of traditional pork are more likely to buy the safe pork. The respondents who have more number of family members are less likely to pay for the safe pork at the significant level of $1 \%$. The possible explanations could be that families with more members spend more on

${ }^{14}$ Calculated by the formula $L R=-2\left(L L_{1}-L L_{2}\right)$, where $L L_{\mathrm{x}}$ is the log-likelihood statistics for the different models.

${ }^{15}$ The degrees of freedom are given by the difference in the numbers of parameters estimated in the two models. 
food and foodstuffs, so their expenditures could increase significantly if they agree to pay more for the safe pork. The study also shows the respondents with a larger proportion of elderly and children are more likely to accept to buy the safe pork at the significant level of $10 \%$.

\section{Conclusion}

This study used the CVM to estimate urban consumer's demand for the proposed safe pork in the Vietnamese Mekong Delta. The results showed that most of the respondents were knowledgeable about pork safety, which is reflected in their understanding of the problem of food safety in the process of pork production and consumption. In general, over $70 \%$ of respondents had knowledge about the situation. In addition, the study also found that $64 \%$ of respondents agreed to pay for the safe pork and they were willing to pay 176,000 VND per $\mathrm{kg}$, which was nearly double compared to the average price of conventional pork in the current market. Regression results showed the acceptability of willingness to pay for the proposed pork was positively influenced by total household income, the price of conventional pork, knowledge of pork safety and the proportion of dependents in the family. In order to develop or promote safe pork in the Vietnamese Mekong Delta, we suggest some following recommendations.

First, the authorities should raise consumer's awareness of the important role of safe food for their health via mass media channels or conferences. Second, to protect the health of consumers, it is necessary to encourage the development of reputable companies specializing in safe pork production with closed feeding and slaughtering chain. This chain meets the requirements such as clear origin, clean label; the processes of slaughter, transportation and sale ensure food safety standard of the Ministry of Agriculture and Veterinary Department. The proposed safe pork could be sale at a price up to double compared with the price of conventional pork. Moreover, food companies should focus on the target group of families with children and the elderly as they are very concerned about health issues. Finally, the authorities should enhance to inspect or check the quality and origin of food to protect the rights of consumers and strengthen their confidence.

Acknowledgements: This study is funded in part by Vietnamese Ministry of Education and Training (MOET) and the Technical Cooperation Project "Building capacity for Can Tho University to be an excellent institution of education, scientific research and technology transfer" of JICA. Our warmest thanks go to the staff and students in the Department of Environmental and Resource Economics, College of Economics, Can Tho University for assisting in data collection.

Conflicts of Interest: The authors declare no conflict of interest

\section{References}

Anh, N. (2015). The dismay of banned substances in animal husbandry.

Anh, N. (2015). Processing of rotten pork in Vietnam.

Bach, G. (2015). An increase in pumping water into pigs before slaughtering.

Carson, R. T., Flores, N. E. \& Meade, N. F. (2001). Contingent valuation: Controversies and evidence. Environmental \& Resource Economics, 19(2), 173-210.

Dam, N. D., Canh, D. X., Ha, N. T. T., Tan, N. V. \& Thieu, N. D. (2012). Vietnam Organic Agriculture: An overview on current status and some success activities.

Dan, T. Y. \& Duyen, T. T. T. (2010). Evaluating the awareness of the community about the conservation of the Vietnamese Sarus crane. Can Tho Journal of Science, 16b, 32-41.

Dinh, Q. (2015). Serious violations of food safety in slaughterhouses.

Hai, N. M., Moritaka, M. \& Fukuda, S. (2013). Willingness to Pay for Organic Vegetables in Vietnam: An Empirical in Hanoi capital. J. Fac. Agr., Kyushu Univ, 58(2), 449-458.

Han, B. (2015). The use of banned substances in livestock.

Hanemann, W. M. \& Kanninen, B. (1998). The Statistical analysis of discrete-response data. Working Paper No.798, Department of Agricultural and Resource Economics and Policy, University of California, Berkeley.

Hieu, D. (2015). Development of livestock herd in the first 6 months of 2015.

Khai, H. V. \& Yabe, M. (2013). Impact of Industrial Water Pollution on Rice Production in Vietnam. In N. 
W. T. Quinn (Ed.), International Perspectives on Water Quality Management and Pollution Control (pp. 61-85): InTech Publishing.

Khai, H. V. \& Yabe, M. (2014). The demand of urban residents for the biodiversity conservation in U Minh Thuong National Park, Vietnam. Agricultural and Food Economics, 2(1), 10.

Khai, H. V. \& Yabe, M. (2015). Consumer preferences for agricultural products considering the value of biodiversity conservation in the Mekong Delta, Vietnam. Journal for Nature Conservation, 25, 62-71.

Khai, H. V. (2015). Assessing Consumer Preferences for Organic Vegetables: A Case Study in the Mekong Delta, Vietnam. Information Management and Business Review, 7(1), 41-47.

Khoi, P. D. \& T. T. Ngan (2014). Willingness to pay of the Mekong households for a biodiversity conservation program at Bac Lieu Bird Sanctuary. Journal of Economics and Development, 208, 17-26.

Krinsky, I. \& Robb, A. (1986). On Approximating the Statistical Properties of Elasticities. Rev Econ Stat, 68(4), $715-719$.

Loureiro, M. L. \& Hine, S. (2002). Discovering niche markets: A comparison of consumer willingness to pay for local (Colorado grown), organic, and GMO-free products. Journal of Agricultural and Applied Economics, 34(3), 477-488.

Miller, G. Y. \& Unnevehr, L. J. (2001). Characteristics of consumers demanding and their willingness to pay for certified safer pork. Journal of Agribusiness, 19(2), 101-120.

Ngan L. \& Chien, H. A. (2015). Horrifying about injection with sleeping pills and pumping water into pigs.

Nghia, T. (2015). Vietnam's GDP per capita in 2014 exceeds USD 2,000.

Ngoan, T. (2015). Dirty food causes 2.2 million people die each year.

Nguyen, H. (2014). The soaked pork still like fresh after the three days.

Ridker, R. G. (1971). Economic Costs of Air Pollution Studies: Praeger Publishers.

Robert, K. D. (1963). The Value of Outdoor Recreation: An Economic Study of the Maine Woods. (PhD dissertation), Harvard University.

Simmons, L. \& Scott, S. (2008). Organic Agriculture and "Safe" Vegetables in Vietnam: Implications for Agro-Food System Sustainability. Department of Geography, University of Waterloo, Canada.

Thai, V. \& H. Minh (2015). Rearing injection of sedative to pigs before slaughtering.

Tsakiridou, E., Zotos, Y. \& Mattas, K. (2006). Employing a Dichotomous Choice Model to Assess Willingness to Pay (WTP) for Organically Produced Products. Journal of Food Products Marketing, 12(3), 59-69.

Yen, L. (2015). Ho Chi Minh City: Warning animal meat "swallow" antibiotics.

Venkatachalam, L. (2004). The contingent valuation method: a review. Environmental Impact Assessment Review, 24(1), 89-124.

Wattage, P. (2002). Effective Management Biodiversity Conservation in Sri Lankan Coastal Wetlands: CVM1 - Literature Review: University of Portsmouth Cemare, UK.

Wong, J. (2009). Willingness to pay for environmentally friendly beef in Georgia. Doctoral dissertation, University of Georgia.

Yao, R. \& Kaval, P. (2008). Valuing Biodiversity Enhancement in New Zealand Working Paper in Economics 08/07, Economics Department, University of Waikato, Private Bag 3105, Hamilton, New Zealand.

Yin, S. J., Wu, L. H., Du, L. \& Chen, M. (2010). Consumers' purchase intention of organic food in China. Journal of the Science of Food and Agriculture, 90(8), 1361-1367. 